\title{
ANALISA PERBANDINGAN METODE CERTAINTY FACTOR DAN DEMPSTER SHAFER PADA SISTEM PAKAR DIAGNOSA PENYAKIT DIABETES MELITUS
}

\author{
Amanda Patria Putra1, Cahya Rahmad ${ }^{2}$ \\ 1,2 Jurusan Teknologi Informasi, Politeknik Negeri Malang \\ 1. amandapatria@gmail.com, ${ }^{2}$ cahya.rahmad@yahoo.com
}

\begin{abstract}
Abstrak
Penelitian sistem pakar diagnosa penyakit diabetes melitus telah beberapa kali dilakukan dengan dua metode berbeda yaitu certainty factor dan dempster shafer. Meski masing-masing peneliti menyatakan telah berhasil dalam jurnalnya, namun metode manakah sebenarnya yang lebih tepat digunakan pada diagnosa jenis penyakit diabetes melitus, yang mana gejala-gejalanya hampir sama. Certainty factor merupakan metode sistem pakar yang tujuannya untuk mengakomodasi ketidakpastian pemikiran seorang pakar dengan nilai kepastian, sedangkan dempster shafer merupakan teori pembuktian matematika berdasarkan nilai belief dan plausability. Untuk membandingkan keduanya, dibuatlah suatu prototipe sistem pakar dengan basis pengetahuan dan sampel 100 data pasien yang sama. Dari hasil analisa statistik, kesimpulannya, ada perbedaan hasil diagnosa antara kedua metode dan metode dempster shafer lebih tepat digunakan pada sistem pakar diagnosa penyakit diabetes melitus.
\end{abstract}

Kata kunci : sistem pakar, diabetes melitus, certainty factor, dempster shafer

\section{PENDAHULUAN}

\subsection{Latar belakang}

Pengembangan aplikasi sistem pakar diagnosa penyakit diabetes melitus menjadi salah satu upaya mendeteksi penyakit sedini mungkin. Dari referensi yang ada, dapat ditemukan beberapa jurnal sistem pakar diagnosa penyakit diabetes melitus menggunakan dua metode berbeda yaitu certainty factor dan dempster shafer.

Adanya penerapan metode berbeda terhadap objek yang sama, perlu dilakukan analisa perbandingan agar diketahui metode mana yang lebih tepat untuk diterapkan pada sistem pakar diagnosa penyakit diabetes melitus.

\subsection{Masalah}

a. Adakah perbedaan hasil diagnosa antara sistem pakar diagnosa penyakit diabetes melitus yang menggunakan metode certainty factor dengan dempster shafer?

b. Manakah diantara metode certainty factor dan dempster shafer yang lebih tepat untuk diterapkan pada sistem pakar diagnosa penyakit diabetes mellitus?

\subsection{Batasan Masalah}

a. Penentuan gejala dan nilai kepercayaan berasal dari dokter dan berbagai sumber pustaka b. Jenis penyakit yang dibahas yakni, diabetes melitus tipe 1, tipe 2, dan gestasional.

c. Sistem pakar berbasis web menggunakan framework Codeigniter dengan bahasa pemrograman PHP dan basis data MySQL.

d. Analisa perbandingan metode certainty factor dan dempster shafer berdasarkan pembahasan statistika deskriptif dan uji hipotesa.

\section{LANDASAN TEORI}

\subsection{Diabetes melitus}

Diabetes melitus adalah bertambahnya gula darah di dalam tubuh seseorang karena insulin yang dihasilkan oleh pankreas tidak mencukupi untuk menyeimbangkan kadar gula yang masuk dalam tubuh.

a. Diabetes melitus tipe 1: diabetes yang terjadi karena berkurangnya rasio insulin dalam sirkulasi darah.

b. Diabetes melitus tipe 2: diabetes yang terjadi karena kelainan metabolisme yang disebabkan oleh mutasi pada banyak gen, termasuk yang menyebabkan disfungsi sel beta.

c. Diabetes Melitus tipe 3 (gestasional): diabetes yang terjadi pada kehamilan, melibatkan kombinasi dari kemampuan reaksi dan pengeluaran hormon insulin yang tidak cukup. 


\subsection{Sistem Pakar}

Sistem pakar muncul untuk memecahkan masalah, karena sistem pakar menggunakan pengetahuan seorang pakar yang dimasukkan ke dalam komputer sebagai basis pengetahuan.

Tabel 1 Interpretasi Pakar

\begin{tabular}{|l|l|}
\hline Unknown (tidak tahu) & 0.2 \\
\hline Maybe (mungkin) & 0.4 \\
\hline Probably (kemungkinan besar) & 0.6 \\
\hline Almost certainly (hampir pasti) & 0.8 \\
\hline Definitely (pasti) & 1.0 \\
\hline
\end{tabular}

\subsection{Certainty Factor}

Certainty factor adalah salah satu metode sistem pakar yang tujuannya untuk mengakomodasi ketidakpastian pemikiran seorang pakar.

Aturan dengan evidence E tunggal dan hipotesis $\mathrm{H}$ tunggal:

$\mathrm{CF}(\mathrm{H}, \mathrm{E})=\mathrm{CF}(\mathrm{E}) \times \mathrm{CF}$ (Aturan)

Kombinasi dua buah aturan dengan gejala berbeda (E1 dan E2), tetapi hipotesis sama:

$\mathrm{CF} 1+\mathrm{CF} 2$ (1-CF1) jika CF1,CF2 >0

\subsection{Dempster Shafer}

Dempster shafer merupakan suatu teori pembuktian berdasarkan belief dan plausability $\mathrm{Pl}(\mathrm{H})=1-\operatorname{Bel}(\mathrm{H})$

$$
\mathrm{M}_{3}(\mathrm{z})=\frac{\sum x \cap y=z m_{1}(X) \cdot m_{2}(Y)}{1-\sum x \cap y=\emptyset m_{1}(X) \cdot m_{2}(Y)}
$$

\section{METODOLOGI PENELITIAN}

\subsection{Tahapan Penelitian}

a. Mengidentifikasi Masalah

Metode manakah sebenarnya yang lebih tepat digunakan pada diagnosa jenis penyakit diabetes melitus, yang mana gejala-gejalanya hampir sama.

b. Menyusun Kerangka Pemikiran

Membangun prototipe sistem pakar diagnosa yang menggunakan kedua metode dengan unit analisa penelitian data rekam medis 100 pasien diabetes melitus Rumah Sakit Islam Unisma Malang, maka akan diperoleh hasil diagnosa pasien dari kedua metode.

c. Merumuskan Hipotesis

Berlandaskan dari kerangka pemikiran, selanjutnya dirumuskan dugaan awal atau jawaban sementara terhadap masalah penelitian yang nantinya akan diuji kebenarannya.

d. Menguji Hipotesis Secara Empirik

Hipotesis diuji berdasarkan data hasil diagnosa yang kemudian diolah dengan statistika deskriptif serta teori keputusan statistik.

e. Melakukan Pembahasan
Dari semua informasi yang diperoleh, dilakukan pembahasan terhadap kedua metode variabel penelitian.

f. Menarik Kesimpulan Menarik kesimpulan dari seluruh kegiatan penelitian yang akan menjawab masalah penelitian, membuktikan hipotesis.

\subsection{Basis Pengetahuan}

Tabel 2 Basis Pengetahuan

\begin{tabular}{|c|c|c|c|c|}
\hline \multirow{2}{*}{ No } & \multirow{2}{*}{ Gejala } & \multicolumn{3}{|c|}{ Densitas } \\
\hline & & DM1 & DM2 & DMG \\
\hline \multicolumn{5}{|c|}{ GULA DARAH } \\
\hline 1 & GDA $>=200$ & 0.8 & 0.8 & 0.8 \\
\hline 2 & GDP $>=126$ & 0.8 & 0.8 & 0.8 \\
\hline 3 & GD2PP $>=200$ & 0.8 & 0.8 & 0.8 \\
\hline 4 & GDA 100-199 & 0.4 & 0.4 & 0.4 \\
\hline 5 & GDP $100-125$ & 0.4 & 0.4 & 0.4 \\
\hline 6 & GD2PP 140-199 & 0.4 & 0.4 & 0.4 \\
\hline \multicolumn{5}{|c|}{ KELUHAN KLASIK } \\
\hline 7 & Poliuria & 0.6 & 0.6 & 0.6 \\
\hline 8 & Polifagia & 0.6 & 0.6 & 0.6 \\
\hline 9 & Polidipsia & 0.6 & 0.6 & 0.6 \\
\hline 10 & Berat turun & 0.6 & 0.6 & 0.6 \\
\hline \multicolumn{5}{|c|}{ KELUHAN LAIN } \\
\hline 11 & Lemah Badan & 0.4 & 0.4 & 0.4 \\
\hline 12 & Kesemutan & 0.4 & 0.4 & 0.4 \\
\hline 13 & Gatal & 0.4 & 0.4 & 0.4 \\
\hline 14 & Mata Kabur & 0.4 & 0.4 & 0.4 \\
\hline 15 & Luka & & 0.6 & \\
\hline 16 & Disfungsi Ereksi & & 0.6 & \\
\hline 17 & Pruntus Vulvae & & 0.6 & \\
\hline \multicolumn{5}{|c|}{ FAKTOR RISIKO } \\
\hline 18 & Riwayat DM & 0.5 & 0.5 & 0.5 \\
\hline 19 & Umur $>=40$ & & 0.5 & \\
\hline 20 & Umur $<40$ & 0.5 & & \\
\hline 21 & R.lahirkan bayi $>4 \mathrm{~kg}$ & & & 0.6 \\
\hline 22 & Hamil & & & 0.6 \\
\hline
\end{tabular}

\subsection{Hipotesis}

a. Ada perbedaan hasil diagnosa antara sistem pakar diagnosa penyakit diabetes melitus yang menggunakan metode certainty factor dengan dempster shafer.

b. Metode dempster shafer lebih tepat untuk diterapkan pada sistem pakar diagnosa penyakit diabetes mellitus. 


\section{ANALISIS DAN PERANCANGAN}

\subsection{Analisis Sistem}

Kebutuhan akan hasil diagnosa yang lebih tepat menjadi alasan kuat yang melandasi penelitian ini. Dibangunnya prototipe sistem pakar diagnosa penyakit diabetes melitus dengan basis pengetahuan yang sama, data gejala pasien yang sama, namun dengan dua metode berbeda akan membuktikan adakah perbedaan diantara keduanya, dan manakah yang lebih mendekati benar.

\subsection{Analisis Kebutuhan}

Akses sistem dibagi menjadi tiga kategori hak akses:

- tamu, akses pengguna tanpa login;

- admin, akses pengguna yang memanipulasi basis pengetahuan;

- pasien, akses pengguna yang melakukan konsultasi.

Sistem mampu melakukan diagnosa certainty factor dan dempster shafer:

- pasien memasukkan data gula darah, umur dan centang gejala;

- sistem menyaring data gejala sesuai jenis kelamin pasien;

- pada halaman diagnosa certainty factor, memungkinkan pasien dapat memilih nilai kepastian gejala berdasarkan tingkat kepercayaannya sendiri;

- diagnosa hanya dapat ditegakkan jika syarat penegakan diagnosa diabetes melitus terpenuhi;

- sistem menampilkan hasil diagnosa berupa gejala terpilih, nama penyakit dan nilai kepercayaannya.

Dalam pembangunan prototipe sistem pakar diagnosa penyakit diabetes melitus dibutuhkan beberapa spesfikasi perangkat keras dan perangkat lunak. Perangkat keras yang dibutuhkan antara lain, CPU Intel Core i3, memori RAM 1 GB atau lebih, dan ruang bebas hard disk sekitar 1,5 GB. Sedangkan perangkat lunaknya antara lain, sistem operasi Windows 8.164 bit, Xampp 5.6.3, Google Chrome 43.0.2, SPSS dan Sublime Text 3.0.

\subsection{Perancangan Sistem}

Work Breakdown Structure merupakan hal penting dalam perencanaan suatu proyek, dimana pembagian wilayah kerjanya akan menjadi terstruktur.

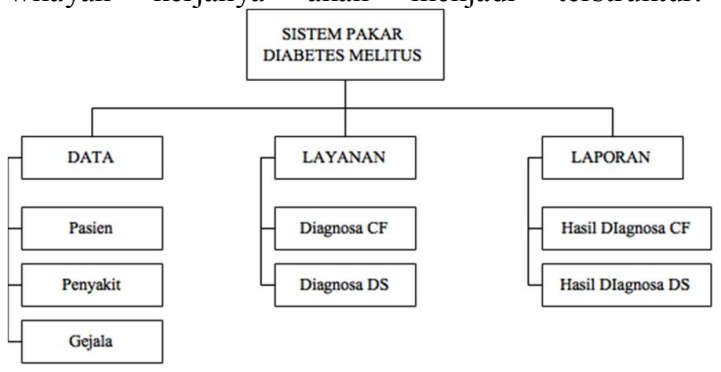

Gambar 1. WBS
Perancangan use case menekankan pada "siapa" melakukan "apa" dalam lingkungan sistem perangkat lunak akan dibangun.

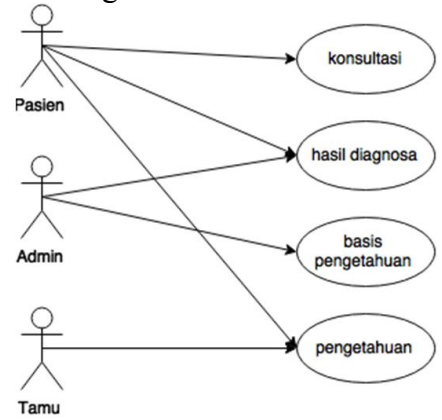

Gambar 2 Use case

Perancangan bagan alir berikut menunjukkan urutan algoritma diagnosa:

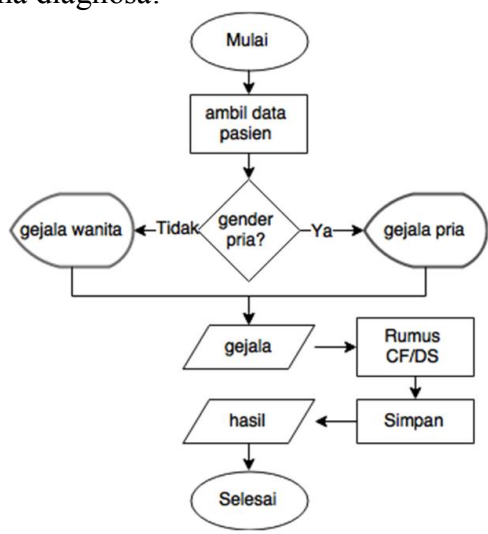

Gambar 3 Bagan alir

ERD merupakan model yang mendeskripsikan hubungan antar data dalam basis data. Tiap-tiap struktur direpresentasikan dengan notasi dan simbol yang telah diatur.

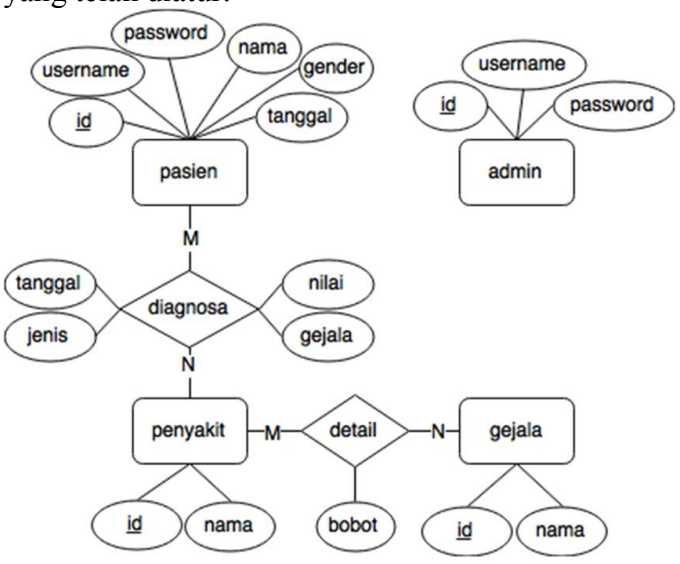

Gambar 4. ERD

\section{IMPLEMENTASI}

\subsection{Basis data}

Sesuai dengan perancangan ERD yang sudah dibuat, pada implementasi dibuatlah 6 tabel dengan rincian 4 tabel entitas kuat yaitu pasien, penyakit, 
gejala, admin serta 2 tabel entitas lemah yaitu diagnosa dan detail gejala. Masing-masing tabel berfungsi menyimpan data sesuai nama tabelnya.

\subsection{Tamu}

Hak akses tamu yang dimaksud merupakan hak akses bagi pengguna tanpa melakukan login atau daftar.

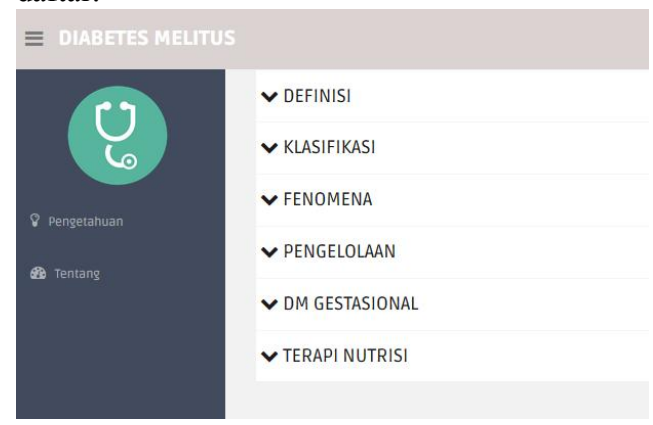

Gambar 5. Tamu

\subsection{Admin}

Admin dapat memanipulasi data gejala, penyakit, detail gejala dan melihat hasil diagnosa pasien.

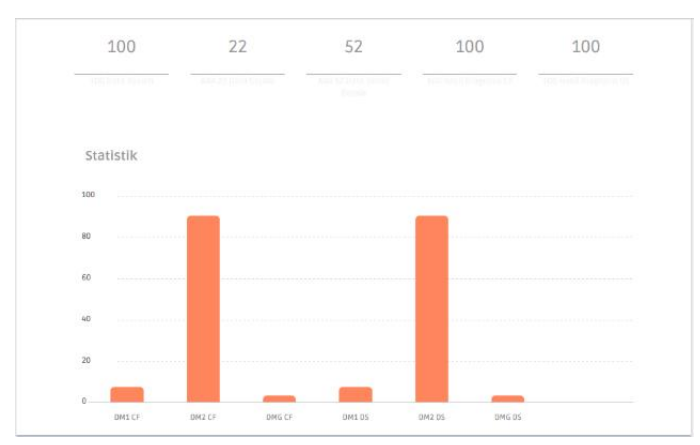

Gambar 6. Admin

\subsection{Pasien}

Pada halaman diagnosa $\mathrm{CF}$, pasien bisa melakukan konsultasi terhadap sistem menggunakan metode certainty factor. Pasien mengisikan data gula darah, umur, gejala disertai tingkat kepercayaannya terhadap masing-masing gejala yang dialami. Nilai kepastiannya direpresentasikan dalam "kurang tahu", "mungkin", "kemungkinan besar", "hampir pasti" dan "pasti".

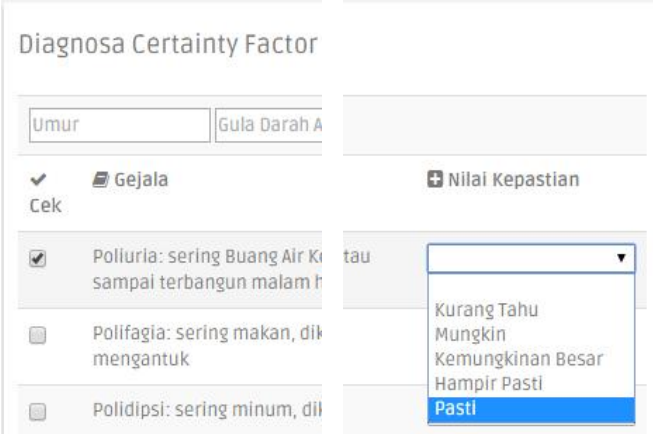

Gambar 7. Diagnosa CF

Pada halaman diagnosa DS pasien bisa melakukan konsultasi terhadap sistem menggunakan metode dempster shafer. Pasien mengisikan data gula darah, umur, dan gejala. Perbedaannya dengan certainty factor, dalam borang dempster shafer tidak ada nilai kepercayaan dari pasien.

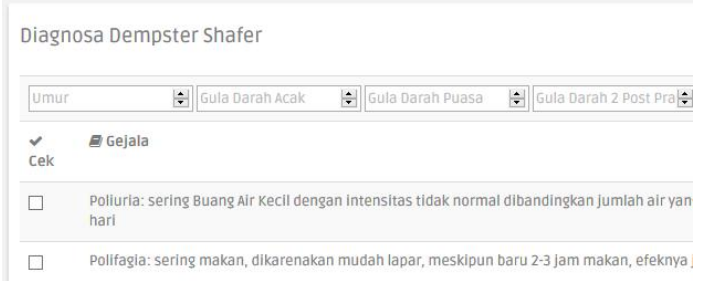

Gambar 8. Diagnosa DS

Hasil diagnosa menampilkan:

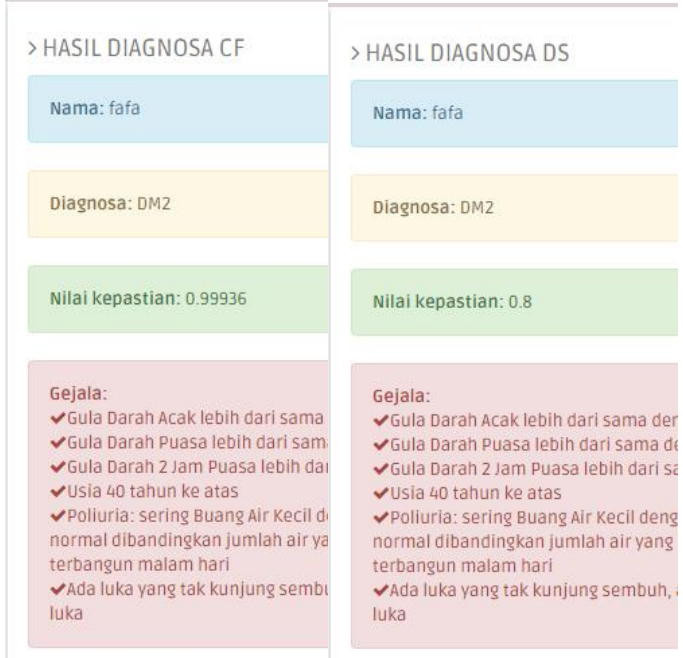

Gambar 9. Hasil diagnosa

\section{PENGUJIAN DAN PEMBAHASAN}

\subsection{Pengujian Black box}

Dilakukan pengujian pada semua halaman dengan melakukan inputan valid maupun invalid. Dan mengecek apakah sistem memberikan respon atau keluaran pesan kesalahan yang benar. Hasilnya semua pengujian black box berhasil, artinya sistem berjalan sesuai yang diharapkan. 
Contoh pengujian penegakan diagnosa:

Sistem berhasil menangani masukan yang tidak sesuai syarat penegakan diagnosa.

\section{Diagnosa Certainty Factor}

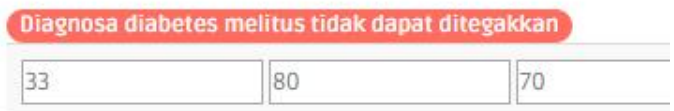

Gambar 10. Pengujian blackbox

\subsection{Pengujian Manual}

Pengujian manual dilakukan untuk membuktikan bahwa sistem sudah berjalan sesuai perhitungan metode certainty factor maupun dempster shafer. Maksud dari perhitungan manual dalam hal ini adalah, dilakukan perhitungan diagnosa menggunakan kedua metode secara manual, dengan menghitung gejala dan nilainya satu persatu.

akurasi CF, DS terhadap manual

$$
\begin{aligned}
& =\frac{\text { jumlah uji benar }}{\text { jumlah data }} \\
& =\frac{100}{100} \times 100 \%=100 \%
\end{aligned}
$$

akurasi CF, DS terhadap dokter

$$
\begin{aligned}
& =\frac{\text { jumlah diagnosa benar }}{\text { jumlah data }} \\
& =\frac{99}{100} \times 100 \%=99 \%
\end{aligned}
$$

Dari pengujian manual yang telah dilakukan, diperoleh akurasi kedua metode sama $100 \%$ terhadap perhitungan manual, yang menandakan bahwa sistem telah berhasil menerapkan metode certainty factor dan dempster shafer. Akurasi kedua metode terhadap diagnosa dokter sama bernilai $99 \%$. Kesalahan terjadi pada pasien 74 , kedua metode mendiagnosa penyakit DM1 sedangkan seharusnya diagnosa dokter adalah DM2. Hal ini terjadi bukan karena kesalahan penerapan metode, namun basis pengetahuan yang tidak bisa mengatasi kelangkaan gejala atau kurangnya informasi gejala yang dialami pasien 74 . Ini merupakan kejadian langka, dimana pasien diabetes melitus tipe 2 pada umumnya tidak berusia muda. Tentu ada pemicu lain, yang menyebabkan terjadinya disfungsi insulin di usia muda, khususnya pola gaya hidup pasien 74 . Oleh karena itu, bagaimanapun juga diagnosa dokter dengan penanganan secara langsung tetap yang lebih baik.

\subsection{Statistik Deskriptif}

Dari hasil diagnosa sistem data dapat diolah menjadi informasi menggunakan pengolahan data statistik. Setelah data diurutkan dan dikelompokkan dalam kelas-kelas frekuensi, maka diperoleh data histogram seperti berikut:
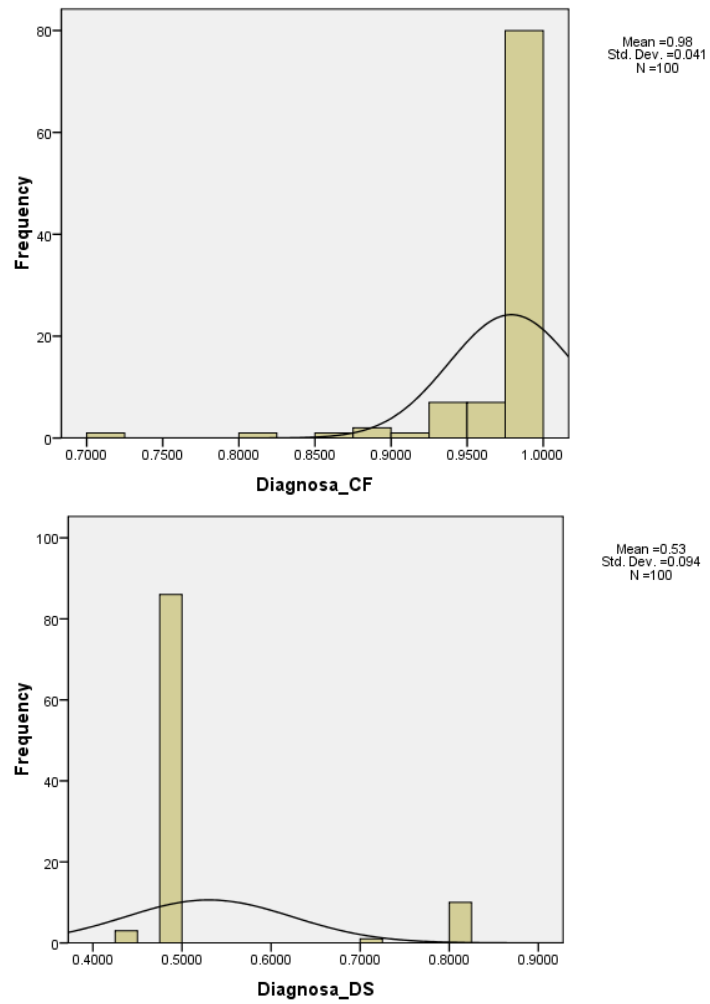

Mean $=0.53$
Std. Devi. $=0.094$
$N=100$

Gambar 11. Histogram CF dan DS

Hasil diagnosa masing-masing metode dicari nilai mean, median, modus, rentang, varian dan simpangan bakunya.

\section{Statistika Deskriptif}

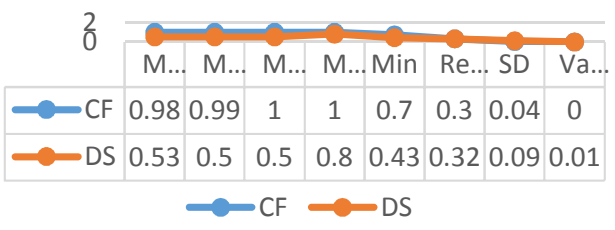

Berdasarkan keluaran statistika deskriptif dan histogram dapat dilihat bahwa:

a. Rata-rata hasil diagnosa CF sebesar 0,979, sedangkan rata-rata diagnosa DS 0,5301.

b. Median CF sebesar 0,994, DS 0,5. Median merupakan nilai tengah jika data diurutkan dan dibagi dua sama besar. Hal ini berarti $50 \%$ hasil diagnosa diatas median dan $50 \%$ hasil diagnosa di bawah median.

c. Nilai modus CF 0,996 , DS 0,5 . Artinya nilai hasil diagnosa yang sering muncul pada CF 0,996 yaitu sebanyak 14 kali, dan pada DS 0,5 yaitu sebanyak 86 kali.

d. Standar deviasi CF sebesar 0,04118, DS sebesar 0,094. Standar deviasi atau simpangan baku digunakan untuk memperkirakan penyebaran data populasi berdasarkan rata-rata sampel. 


\subsection{Uji Hipotesis 1}

H1: Ada perbedaan hasil diagnosa antara sistem pakar diagnosa penyakit diabetes melitus yang menggunakan metode certainty factor dengan dempster shafer.

H0: Tidak ada perbedaan hasil diagnosa antara sistem pakar diagnosa penyakit diabetes melitus yang menggunakan metode certainty factor dengan dempster shafer.

Untuk membuktikan kebenaran hipotesis digunakan Uji Mann Whitney karena dua sampel hasil diagnosa bersifat independen, nonparametrik. Untuk mengujinya, digunakan alat bantu SPSS dengan Uji Nonparametrik Mann Whitney.

Tabel 3. Pencarian peringkat

\begin{tabular}{|l|c|r|r|}
\hline & $\mathrm{N}$ & Mean Rank & \multicolumn{1}{c|}{ Sum of Ranks } \\
\hline CF & 100 & 150.39 & 15039,00 \\
\hline DS & 100 & 50.61 & 5061,00 \\
\hline Total & 200 & & \\
\hline
\end{tabular}

Tabel 4. Hasil Uji U

\begin{tabular}{|l|r|}
\hline & Hasil Diagnosa \\
\hline Mann-Whitney U & 11,000 \\
\hline Wilcoxon W & 5061,000 \\
\hline Z & -12.710 \\
\hline Asymp. Sig. (2-tailed) & 0,000 \\
\hline
\end{tabular}

Kriteria pengujian dengan tingkat signifikansi $\alpha 0,05$ (keyakinan 95\%):

a. Jika Probabilitas kesalahan $<0,05$ maka H0 ditolak. b. Jika Probabilitas kesalahan $\geq 0,05$ maka $\mathrm{H} 0$ diterima

Dari hasil Uji Mann Whitney diketahui bahwa probabilitas kesalahan $(0,000)<0,05$, maka $\mathrm{H} 0$ ditolak.

\subsection{Uji Hipotesis 2}

H1: Metode dempster shafer lebih tepat untuk diterapkan pada sistem pakar diagnosa penyakit diabetes mellitus.

H0: Metode dempster shafer tidak lebih tepat untuk diterapkan pada sistem pakar diagnosa penyakit diabetes mellitus.

Untuk mengetahui mana yang lebih tepat, digunakan alat bantu SPSS dengan Uji T dua sampel independen dengan asumsi data terdistribusi normal, menghasilkan:

\begin{tabular}{|l|l|l|l|l|}
\multicolumn{5}{|c}{ Tabel 5. Statistik Deskriptif } \\
\hline & $\mathrm{N}$ & Mean & $\begin{array}{l}\text { Std. } \\
\text { Dev }\end{array}$ & $\begin{array}{l}\text { Std. Error } \\
\text { Mean }\end{array}$ \\
\hline DS & 100 & 0.530099 & $\begin{array}{l}0.0940 \\
1\end{array}$ & 0.009401 \\
\hline CF & 100 & 0.978998 & 0.0412 & 0.00412 \\
\hline
\end{tabular}

Tabel 6. Hasil Uji T

\begin{tabular}{|c|c|c|c|}
\hline & & $\begin{array}{l}\text { Equal } \\
\text { variances } \\
\text { assumed } \\
\end{array}$ & $\begin{array}{l}\text { Equal } \\
\text { variances } \\
\text { not assumed }\end{array}$ \\
\hline \multicolumn{2}{|l|}{$\mathrm{F}$} & 18.647 & \\
\hline \multicolumn{2}{|l|}{ Sig. } & 0,000 & \\
\hline \multicolumn{2}{|l|}{$\mathrm{t}$} & -43.738 & -43.738 \\
\hline \multicolumn{2}{|l|}{ df } & 198 & 135.646 \\
\hline \multicolumn{2}{|c|}{ Sig. (2-tailed) } & 0.065 & 0.065 \\
\hline \multicolumn{2}{|l|}{ Mean Differ } & -0.448899 & -0.448899 \\
\hline \multicolumn{2}{|c|}{ Std. Error Differ } & 0.0102633 & 0.0102633 \\
\hline \multirow{2}{*}{$\begin{array}{l}95 \% \\
\text { Confidence }\end{array}$} & Lower & -0.4691384 & -0.4691957 \\
\hline & Upper & -0.4286596 & -0.4286023 \\
\hline
\end{tabular}

Kriteria pengujian dengan tingkat signifikansi $\alpha 0,05$ (keyakinan 95\%):

a. Jika Probabilitas kesalahan $<0,05$ maka H0 ditolak. b. Jika Probabilitas kesalahan $\geq 0,05$ maka $\mathrm{H} 0$ diterima

Dari hasil diketahui bahwa probabilitas kesalahan $(0,000)<0,05$ maka H0 ditolak.

\section{KESIMPULAN}

Dari semua kegiatan penelitian yang telah dilakukan, maka dapat ditarik kesimpulan bahwa:

a. Hasil Uji Mann Whitney dengan tingkat signifikansi 0,05 membuktikan bahwa ada perbedaan hasil diagnosa antara sistem pakar diagnosa penyakit diabetes melitus yang menggunakan metode certainty factor dengan dempster shafer.

b. Hasil Uji $\mathrm{T}$ dengan tingkat signifikansi 0,05 membuktikan bahwa metode dempster shafer lebih tepat untuk diterapkan pada sistem pakar diagnosa penyakit diabetes mellitus.

\section{Daftar Pustaka:}

Arief, M. Rudyanto. (2011): Pemrograman Web dinamis menggunakan PHP dan MySql. Yogyakarta: Andi

Jogiyanto, HM. (2011): Metodologi Penelitian Sistem Informasi. Yogyakarta: Andi

Mboih, N. (2014): Peraturan Menteri Kesehatan Republik Indonesia Nomor 5 Tahun 2014 Tentang Panduan Praktik Klinis Bagi Dokter. Jakarta: Kementrian Kesehatan Republik Indonesia

Spiegel, M.R. dan Larry J. Stephens. (2007): Probabilitas dan Statistik Edisi Ketiga. Jakarta: Erlangga

Sutojo dkk. 2011. Kecerdasan Buatan. Yogyakarta: Andi. 